\title{
Targeting innate immunity to downmodulate adaptive immunity and reverse type I diabetes
}

\author{
Arata Itoh \\ William M Ridgway \\ Division of Immunology, Allergy \\ and Rheumatology, University of \\ Cincinnati College of Medicine. \\ Cincinnati, $\mathrm{OH}$, USA
}

This article was published in the following Dove Press journal:

ImmunoTargets and Therapy

19 May 2017

Number of times this article has been viewed
Correspondence: William M Ridgway Division of Immunology, Allergy and Rheumatology, University of Cincinnati College of Medicine, Medical Science Building, 23I Albert Sabin Way, Room 7505, Mail Location \#0563 Cincinnati, OH 45267, USA

Tel + I 513558555 I

Email ridgwawm@ucmail.uc.edu
Abstract: Type 1 diabetes (T1D) is characterized by specific destruction of pancreatic insulinproducing beta cells accompanied by evidence of beta-cell-directed autoimmunity such as autoreactive $\mathrm{T}$ cells and islet autoantibodies (IAAs). Currently, T1D cannot be prevented or reversed in humans. T1D is easy to prevent in the nonobese diabetic (NOD) spontaneous mouse model but reversing new-onset T1D in mice is more difficult. Since the discovery of the T-cell receptor in the 1980s and the subsequent identification of autoreactive T cells directed toward beta-cell antigens (eg, insulin, glutamic acid decarboxylase), the dream of antigen-specific immunotherapy has dominated the field with its promise of specificity and limited side effects. While such approaches have worked in the NOD mouse, however, dozens of human trials have failed. Broader immunosuppressive approaches (originally cyclosporine, subsequently anti-CD3 antibody) have shown partial successes (e.g., prolonged $\mathrm{C}$ peptide preservation) but no major therapeutic efficacy or disease reversal. Human prevention trials have failed, despite the ease of such approaches in the NOD mouse. In the past 50 years, the incidence of T1D has increased dramatically, and one explanation is the "hygiene hypothesis", which suggests that decreased exposure of the innate immune system to environmental immune stimulants (e.g., bacterial products such as Toll-like receptor (TLR) 4-stimulating lipopolysaccharide [LPS]) dramatically affects the adaptive immune system and increases subsequent autoimmunity. We have tested the role of innate immunity in autoimmune T1D by treating acute-onset T1D in NOD mice with anti-TLR4/MD-2 agonistic antibodies and have shown a high rate of disease reversal. The TLR4 antibodies do not directly stimulate T cells but induce tolerogenic antigen-presenting cells (APCs) that mediate decreased adaptive T-cell responses. Here, we review our current knowledge and suggest future prospects for targeting innate immunity in T1D immunotherapy. Keywords: type 1 diabetes, antigen-specific therapy, innate immunity, Toll-like receptors

\section{Type I diabetes (TID): prevention, treatment, or cure?}

Curing a medical disease generally implies completely removing the pathogenic agents: e.g., killing microbes with specific antibiotic therapy or surgically removing cancer. In T1D, cure implies reversing new-onset T1D and restoring glucose homeostasis. Initial surgical success using the Edmonton protocol in islet transplantation ${ }^{1}$ was tempered by later results showing recurrence of T1D in these grafts. Subsequently, hopes for a medical cure have largely involved "antigen-specific therapies" (refer to the "Curing T1D: antigen-specific approaches" section). In contrast to cure, in most clinical autoimmune diseases (such as rheumatoid arthritis), current approaches do 
not cure the disease: the disease is suppressed or halted by immunosuppressive therapy (e.g., anti-TNF therapies in rheumatoid arthritis). Usually (although not always), when the treatment is stopped, autoimmune disease recurs in rheumatology. This raises a major issue in T1D therapeutics: there is already a treatment for the disease. There has been progress in controlling blood glucose (BG) using rapidacting or long-acting insulin analogs and sensor-augmented insulin pumps for long-term management of hyperglycemia and hypoglycemia. ${ }^{2-5}$ Given that many T1D patients are children otherwise in good health, the existence of insulin therapy makes the risks of many treatment approaches (e.g., bone marrow transplantation with chemoablation or strongly immunosuppressive drugs) prohibitive. The risks of ongoing T1D are considerable, but these risks must be matched up against the risk of any proposed therapy. Ultimately, one must ask in each case of a proposed new therapy what is the risk/benefit of daily treatment over a lifetime, compared to the same risk/benefit analysis of insulin therapy? This is one reason why many have emphasized trying to cure T1D: to avoid the risks of chronic treatment.

\section{Curing TID: antigen-specific approaches}

Evidence that T1D is an organ-specific autoimmune disease has accumulated for over 45 years. ${ }^{6}$ Cell-mediated immunity to insulin in human T1D was shown in $1975 .^{7}$ The development of T-cell cloning ${ }^{8}$ and the discovery of the T-cell receptor genes ${ }^{9}$ rapidly led to the cloning of human $\mathrm{T}$ cells autoreactive to insulin. ${ }^{10,11}$ This led to the concept that T1D could be cured by eliminating specific T cells without affecting the entire T-cell repertoire (and thus inducing global immunosuppression). ${ }^{12}$ An enormous number of studies focused on insulin reactive $T$ cells in $T 1 D$, with the hope that eliminating or otherwise changing the function of these autoreactive $T$ cells could cure the disease without affecting the global T-cell response to infections (i.e., without inducing global immunosuppression). The idea seems simple: why not just remove those $\mathrm{T}$ cells that express autoreactive T-cell receptors from the T-cell repertoire? Unfortunately, this approach has failed in human T1D for both insulin and other autoantigens. More than 20 different human trials of various insulin preparations, given with the hope of either eliminating or anergizing insulin-specific T cells and thus stopping T1D, have failed. ${ }^{13}$ Antigen-specific therapy in general has had no effect on the disease process - it did not halt T1D let alone cure it. Although antigen-specific immunotherapy remains an area of intense interest and investigations, these repeated failures in human trials have dampened initial optimism about this approach. Why has antigen-specific therapy failed so far? The most likely explanation is that by the time of acute disease in humans, epitope spreading has occurred; in other words, $\mathrm{T}$ cells reacting to many islet-related autoantigens are attacking the islet, so that eliminating one set of $\mathrm{T}$ cells is unable to affect the progression of the disease. ${ }^{14}$ Even if insulin is the "original" autoantigenic target, in this scenario, targeting insulin would only work very early in disease (refer to the "Preventing T1D: antigen-specific and nonspecific approaches" section).

\section{Curing or treating TID using broader immunosuppressive approaches targeting adaptive immunity}

Many different nonantigen-specific, but adaptive immunedirected (i.e., directed primarily to $\mathrm{T}$ and $\mathrm{B}$ cells), immunotherapeutic approaches have been tried in the past 30 years. One of the first was cyclosporine A (CsA), which inhibits calcineurin and reduces T-cell inflammatory cytokine production. CsA was quite effective in retrospect, with $20 \%-65 \%$ initial T1D reversal, but severe side effects (renal toxicity) were reported and T1D recurred after the reagent administration ceased. ${ }^{15,16}$ Another approach to adaptive immunity, targeting $\mathrm{T}$ cells with anti-CD3 antibodies, has been thoroughly studied. Anti-CD3 Ab induced $-60 \%$ reversal of newly diagnosed T1D in nonobese diabetic (NOD) mice ${ }^{17}$ by modulating both effector $\mathrm{T}$ cells and regulatory $\mathrm{T}$ cells. Anti-CD3 Ab depleted up to $50 \%$ of peripheral $\mathrm{T}$ cells in a dose-dependent manner ${ }^{18,19}$ by inducing effector T-cell apoptosis. ${ }^{20}$ This treatment also induced anergy in both CD4 and CD8 T cells. ${ }^{21}$ Beta-cell-specific regulatory T cells were differentiated in the periphery, ${ }^{17}$ and these regulatory $\mathrm{T}$ cells were protected from the anti-CD3-mediated depletion or inactivation. ${ }^{20}$ However, these promising results in mice were not replicated in humans; diabetic patients did not obtain long-term preservation of endogenous insulin secretion and showed only a small decrease in exogenous insulin use. ${ }^{22,23}$ A large number of other agents targeting adaptive immunity have been tested in human T1D trials, including anti-CD20, CTLA4-Ig, and many others (well reviewed recently by Kolb and von $\mathrm{Herrath}^{24}$ ). Many of these approaches can temporarily halt loss of beta-cell mass/function (as measured, e.g., by C peptide preservation), but none of them can halt the disease process. New therapeutic approaches are clearly needed, including combination therapies that can synergistically target multiple different immune pathways. ${ }^{25}$ 


\section{Preventing TID: antigen-specific and nonspecific approaches}

The failure to find effective immunotherapies to reverse acute T1D has focused attention on other approaches, including prevention. One impetus for considering prevention is the rapid increase in T1D incidence in many countries since the mid-20th century, which is not explicable by the known genetic predisposition to disease. ${ }^{26}$ In Europe, for example, the incidence of T1D cases has been increasing on the average $3.9 \%$ per annum, which is a near epidemic pace.$^{27}$ If environmental factors are driving this increase, they could be targeted to prevent the disease. What could explain the rising incidence? One explanation is the "hygiene hypothesis", which suggests that insufficient exposure to microbial agents in immune system development predisposes the adaptive immune system to hyperactivity, resulting in increased autoimmune and allergic diseases. ${ }^{28}$ Evidence for the hygiene hypothesis in T1D is increasing. Recently, it was shown that Finnish children, located across the border from Russian, have a much higher incidence of T1D and that this could be explained by exposure to an altered form of lipopolysaccharide (LPS) in altered bacterial flora found in a western European village. ${ }^{29}$ The authors concluded that "Early colonization by immunologically silencing microbiota may thus preclude aspects of immune education", ${ }^{29}$ which can lead to hyperactive adaptive immunity.

Besides hygiene hypothesis, there are several other reasons to consider preventative approaches in T1D. One reason is found in the NOD mouse model: it is very easy to prevent T1D in NOD mice. A peculiarity of the NOD literature is the exaggerated attention paid to prevention vs. disease reversal studies. It was already shown over 12 years ago that 440 studies had been done showing prevention of NOD T1D, while only 23 published protocols attempted to reverse the disease. ${ }^{30}$ In fact, many agents that can prevent NOD T1D cannot reverse it (a good example is LPS: it can prevent NOD T1D but is ineffective after age 10 weeks and does nothing to reverse acute disease ${ }^{31}$ ). Apart from the mouse model, it is now possible to predict human T1D on the basis of autoantibodies: two positive islet autoantibodies (IAAs) predict a rate of development of clinical disease at $\sim 11 \%$ progression per year..$^{32}$ Thus, the presence of two IAAs in children is now considered preclinical human "Stage 1" T1D. ${ }^{33}$ Finally, genetic risks of T1D are increasingly well defined. Ninety percent of European T1D patients have disease susceptibility DR3, DR4, or DQ HLA loci. ${ }^{34}$ Four single nucleotide polymorphisms (SNPs), in DR3, DR4, CTLA4, and INS, can predict T1D with an AUC of 0.72; a full panel of 40 SNPs increases the AUC to $0.87 . .^{35}$

These favorable developments, combined with the failure to effectively treat disease, have led to a renewed emphasis on T1D prevention, as well as many T1D prevention clinical trials. ${ }^{36-38}$ Unfortunately, however, there are serious problems facing any attempt to prevent human T1D. First, prevention trials in high-risk individuals (defined by both autoantibody status and genetic risk) have already failed. The TRIGR trial, which tested the hypothesis that exposure to cow's milk increased T1D incidence and substituted hydrolyzed casein in infant formula, failed to prevent autoantibody formation..$^{37}$ The Diabetes Prevention Trial (DPT-1) to prevent T1D using insulin to tolerize $\mathrm{T}$ cells failed, and nicotinamide failed to prevent progression to T1D in the ENDIT trial. ${ }^{37,39}$ These failures could be attributed to the wrong preventative agent, indeed Trialnet is conducting many additional prevention trials (www.diabetestrialnet.org).

However, there are several other major obstacles facing T1D prevention trials: 1) although, as noted previously, individuals with two IAAs progress to T1D at $\sim 11 \%$ per year, $15 \%-20 \%$ of these individuals still do not develop T1D at 20 years. ${ }^{36}$ This is a major clinical and research problem: how to develop a trial to deal with such variable and prolonged disease development. Moreover, is it feasible to treat children for 10 years or longer with immunosuppressive agents (anti-CD3 antibodies and CTLA4-Ig are examples of agents currently being tested in prevention trials) to achieve prevention - what would the side effect profile be over this prolonged period? 2) Many current studies are performed in populations "enriched" in T1D, however, the vast majority of patients ( $85 \%)$ have no family history of T1D. ${ }^{36}$ Thus, prevention studies would require expansion of autoantibody screening to the entire population. While this is certainly possible, the performance of assays and predictive value of IAAs in the general population (as opposed to enriched populations) is not known. Finally, of course, we simply do not know if the ease with which T1D is prevented in the NOD mouse is translatable to humans. Prevention may simply not work. All of this emphasizes the need to continue to try to develop new approaches for treating the acute disease.

\section{New therapeutic approaches directed to innate immunity: clues from the NOD model}

The NOD mouse, which spontaneously develops autoimmune T1D, has been studied extensively since its 
introduction in 1982, and a large NOD literature has been published showing that virtually every aspect of the immune system is involved. ${ }^{40,41}$ Studies of adaptive immunity have predominated in the NOD literature, due to the spectacular correlation between human and mouse with respect to involvement of MHC Class II, autoreactive T cells against the same autoantigens (insulin, glutamic acid decarboxylase, etc.) in mouse and man, and the presence of similar autoantibodies prior to disease onset. ${ }^{41}$ In addition, genetic studies have found that many non-MHC loci related to immunity were shared between NOD and human T1D patients. ${ }^{42}$ More recently, however, focus has shifted to the role of innate immunity in NOD pathogenesis. The role of environmental factors was originally highlighted by the observation that NOD mice housed in "cleaner" facilities had increased disease incidence. ${ }^{43}$ In fact, NOD mice housed in germ-free facilities had $100 \%$ incidence of T1D (compared to $80 \%$ in NOD female mice housed under conventional conditions). ${ }^{44}$ Wen et $\mathrm{al}^{44}$ pursued these ideas and showed that NOD mice lacking Myd88 (an adapter protein that mediates signaling from multiple innate molecules, including Toll-like receptor [TLR] 4) were completely protected from T1D in the presence of normal flora, but developed $100 \%$ T1D incidence under germ-free conditions. Furthermore, they showed that the Myd88 effect was mediated through the microbiome: treating the germ-free mice with the microbiota from protected mice ameliorated disease. ${ }^{44}$ This revolutionary study initiated an explosion of studies on the role of microbiota in autoimmunity, which has been recently reviewed. ${ }^{45-47}$ In T1D, attention was initially focused on the role of TLR4, which was investigated by making NOD TLR4-/- mice. However, the effect of TLR4 knockout on T1D development has been inconsistent, with studies showing increased, decreased, and no effect on T1D incidence. ${ }^{44,48,49}$ This contradictory evidence is probably explained by the fact that TLR4/ MD-2 signaling is mediated by both TIR-domain-containing adapter inducing IFN- $\beta$ (Trif) and Myd88 adaptor proteins. ${ }^{50}$ Chervonsky et $\mathrm{al}^{51}$ confirmed this by showing that dual Myd88/Trif NOD knockout mice are not protected from T1D in the presence of conventional microbiota (unlike the NOD single Myd88 knockout). This result supports a "balanced signal" hypothesis, meaning that both inflammatory and regulatory responses are induced by the microbiota and that TLR4-mediated Trif signaling causes a tolerizing immune response, which protects against T1D development. ${ }^{51}$ These extremely important studies bring studies of innate immunity, and potential therapeutic approaches to TLR4 signaling, to the forefront in T1D research.

\section{Novel approaches to immunotherapy for TID: targeting innate immunity to regulate adaptive immune responses}

We decided a few years ago to focus our efforts on reversing T1D in NOD mice. While this approach seems obvious, for some reason (perhaps because prevention experiments are easier to do, are more successful, and generate more articles), the field is dominated by prevention studies in NOD. Many of the agents that have been shown to prevent NOD T1D demonstrably cannot reverse acute disease in NOD. One reason for the ineffectiveness of "preventative" agents to reverse disease is that prevention approaches may target earlier, more permissive "checkpoints" in the disease prior to significant inflammation, whereas reversal must address the acute disease. ${ }^{52}$ As discussed previously, by 2005, only 23 attempts to reverse NOD T1D had been reported, with 16 successes, compared to 440 prevention trials. ${ }^{30}$ We estimate that by now there have been published $\sim 1000$ articles showing prevention of NOD T1D and perhaps 40-50 articles on reversal. Clearly, there is much room to define novel reversal pathways in NOD T1D.

The hygiene hypothesis and accumulating evidence showing that environmental influences, particularly the microbiota signaling effect on the TLR4 pathway, played a key role in T1D, suggested to us that innate immunity might be an underdeveloped target in T1D therapy. What could be the mechanistic explanation for the hygiene effect? Antigenpresenting cells (APCs) critically affect adaptive immune responses $^{53}$ and the balance of pathogenic vs. protective T-cell responses ${ }^{54}$; and macrophages/dendritic cells (DCs) are among the first cell types found infiltrating the islet. ${ }^{55}$ NOD mice have developmental defects in macrophages. ${ }^{56}$ Altered immune stimulation of APCs by environmental agents, including variant forms of LPS, could profoundly affect APCs and either enhance or reduce diabetogenesis, in fact this was subsequently demonstrated as mentioned previously. ${ }^{29}$ The invading macrophages in NOD T1D promote disease pathogenesis ${ }^{57}$ by producing proinflammatory cytokines such as TNF- $\alpha .{ }^{55}$ Proinflammatory APCs that do not regulate effector $\mathrm{T}$ cells could explain epitope spreading and thus the inability to treat T1D by targeting a single autoantigen. This critical "cross-talk" between innate and adaptive immunity is thus an attractive therapeutic target in autoimmunity. ${ }^{58}$

We have focused on TLR4 given the literature discussed previously; other TLRs and innate molecules may be suitable 
targets. ${ }^{59}$ TLRs are expressed on innate immune cells including DCs and macrophages. Ten TLRs have been identified in humans (TLR1-10) and 12 (TLR1-9 and TLR11-13) in mice. ${ }^{60}$ There are two TLR subfamilies: cell surface TLRs (TLR1, TLR2, TLR4, TLR5, TLR6, and TLR10) and intracellular TLRs, localized in the endosome (TLR3, TLR7, TLR8, TLR9, TLR11, and TLR12). Each TLR recognizes different molecular structures expressed by various microorganisms. One mechanistic explanation for the hygiene effect, as discussed previously, is that TLR4 interacts with the microbiome to mediate protective/tolerance inducing pathways via the Trif signaling pathways. ${ }^{51}$ Another major immunoregulatory mechanism that attracted our attention to agonist signaling via TLR4 is the induction of "endotoxin tolerance" by submaximal TLR4 signaling. Endotoxin tolerance is induced in hepatic macrophages due to persistent low-level exposure to LPS; this reduces subsequent induction of macrophage activation and reduces inflammation. ${ }^{61,62}$ Endotoxin-tolerized immune cells have a tolerogenic immune response that has profound downregulatory effects on adaptive immunity. ${ }^{63} \mathrm{We}$ hypothesized that converting islet infiltrating macrophages to a tolerogenic phenotype (e.g., by inducing endotoxin tolerance) could alter adaptive T-cell responses and reverse the acute inflammatory state in the diabetic islet. To alter APC function via TLR4 in vivo in acute T1D, we used agonistic TLR4/MD-2 directed antibodies (TLR4-Ab) that had been shown to induce endotoxin tolerance. ${ }^{64,65}$ We tested the effect of TLR4-Ab in acute T1D in mice with serum BG between 200 and $400 \mathrm{mg} / \mathrm{dL}$.

Our approach was extremely effective at reversing acute T1D (even with BG in the $300-400 \mathrm{mg} / \mathrm{dL}$ range) in the vast majority of mice, while control antibody-treated mice or untreated mice rapidly progressed to end-stage T1D (BG $>500 \mathrm{mg} / \mathrm{dL}$ ). ${ }^{66}$ Notably, BG decreased even though we did not treat mice with exogenous insulin. Investigation of islet pathology gave valuable clues to the mechanism of action: TLR4-Ab-treated mice demonstrated increased numbers of islets with reduced inflammation, and the amount of insulin per islet increased compared to mice at the onset of T1D (untreated) or mice treated with control antibody ${ }^{66}$ Investigation of the cellular target of TLR4-Ab revealed that it did not directly affect either T cells or Treg cells, but increased the numbers of macrophages and DCs. APCs downregulated their costimulatory molecule expression and as a result $\mathrm{T}$ cells proliferated less. In addition, interleukin (IL)-10 production increased significantly, along with IL-2, IL-4, and IL-33. ${ }^{66}$ Two weeks after TLR4-Ab treatment, T regulatory cells increased in the periphery. Finally, transfer studies suggested but did not prove that B cells were not necessary for the disease protective effect.

These dramatic results indicate a profound reorganization of the immune response in TLR4-Ab-treated diabetic mice. We are beginning to unravel some of the mechanisms of this treatment effect. We performed RNAseq at 1 week following the second TLR4-Ab treatment in vivo to try to understand this issue. RNAseq revealed a highly significant induction of genes associated with CD11b+Ly6-g+ APCs and a downregulation of T-cell-related genes (W Ridgway, University of Cincinnati, unpublished data, February, 2017). This raised the possibility that rather than simply tolerizing existing APCs, we were inducing an influx of myeloid-derived suppressor cells (MDSCs). MDSCs are a relatively new class of APCs that act to actively suppress $\mathrm{T}$ effector cells. ${ }^{67} \mathrm{MDSC}$ s have been predominantly studied in oncology; infiltration of MDSCs in the tumor environment can suppress the effect of T-cell-mediated immunity against cancer cells. ${ }^{68-70}$ Increasingly, however, it is appreciated that deficient MDSC induction may play a role in autoimmunity. ${ }^{71,72}$ Induction of MDSCs can inhibit autoimmunity, most likely by interacting and suppressing T-cell effector responses. ${ }^{73,74}$ Notably, this is highly consistent with the studies by Ghazarian et $\mathrm{al}^{75}$ who showed that while Coxsackievirus B4 virus can accelerate T1D, natural killer T cell induced MDSCs that infiltrated into the islet, downregulated effector $\mathrm{T}$ cells, and prevented T1D. Although TLR4-Ab is given systemically, therefore, it may act by mobilizing MDSC from the bone marrow whereupon they expand in multiple sites including the pancreatic islet. How they home to the islets, however, is currently unknown. At this point, therefore, our leading hypothesis is that TLR4-Ab induces MDSCs that can actively suppress diabetogenic T cells and reverse T1D. This and related hypotheses are an active area of investigation for our laboratory.

Are there other novel approaches to innate immunity in treating T1D? Many agents targeting innate immunity have been tested to prevent NOD T1D; however, as mentioned previously, this has little correlation with successful treatment of active disease. The tested approaches to reverse T1D have largely focused on adaptive immunity. However, one approach that was highly successful in reversing T1D in NOD included granulocyte-colony stimulating factor (G-CSF) along with an anti-T-cell agent. ${ }^{76}$ We suspect, but do not know, that this approach may mobilize similar suppressive APCs as our TLR4-Ab. A few other approaches to innate immunity have reversed acute T1D in NOD mice. ${ }^{77}$ Both Aralast, a serine protease inhibitor, and Imatinib, a tyrosine kinase inhibitor, have reversed T1D, although their exact effect on innate immunity is not well understood. ${ }^{78,79}$ 
Other therapeutic approaches to T1D may have heretofore unrecognized effects on innate immunity. For example, we have shown that an agonistic antibody to CD137 prevented $\mathrm{T} 1 \mathrm{D},{ }^{80}$ while the splice variant of CD137, soluble CD137 (sCD137) is an immunosuppressive molecule that can both prevent $\mathrm{T} 1 \mathrm{D}^{81,82}$ and ameliorate active T1D (W Ridgway, University of Cincinnati, unpublished data, February, 2017). Our emphasis has been on T cells and Tregs in these studies, but since both CD137 and CD137 ligand are expressed on APCs, the innate immune system may also play a role that needs to be investigated. In terms of human clinical trials, the vast majority have targeted adaptive immunity. G-CSF combination therapy has recently been tested in humans, where it was well tolerated. ${ }^{83}$ Both Aralast and Imatinib human T1D trials have been initiated, but the full results are not yet known. ${ }^{84}$ Therefore, the field of targeted immunotherapy directed to innate immunity is in its infancy in human T1D.

\section{Conclusion}

Overall, our results and the abovementioned studies suggest that many promising approaches will soon be developed targeting innate immunity as a therapeutic pathway in T1D. The ultimate goal is to replicate in humans the intricate immune system "re-education" that we see over the course of TLR4-Ab treatment in mice: an alteration of the numerical and functional immune components active in disease to downregulate autoimmune $\mathrm{T}$ cells (thus overcoming the limitations of antigen-specific therapies that cannot address epitope spreading) and upregulate $\mathrm{T}$ regulatory and APC suppressive functions. Our TLR4-directed approach is promising because it appears to target the same pathways that are understimulated in environments showing a dramatic increase in T1D in the last half century (as explained by the hygiene hypothesis of increased T1D incidence). Since TLR4 agonists are already being tested in other human diseases, ${ }^{85}$ this approach could be translated to human application relatively quickly, whether alone or as a combination therapy with agents that also target the adaptive immune component.

\section{Acknowledgments}

This work was supported by National Institutes of Health (NIH) 1R01DK107541-01A1, NIH 1R21AI120084-01A1, and American Diabetes Association 1-16-IBS-049 to WMR.

\section{Disclosure}

The authors report no conflicts of interest in this work.

\section{References}

1. Shapiro AM, Lakey JR, Ryan EA, et al. Islet transplantation in seven patients with type 1 diabetes mellitus using a glucocorticoid-free immunosuppressive regimen. N Engl J Med. 2000;343(4):230-238.

2. Anderson JH Jr, Brunelle RL, Koivisto VA, et al. Reduction of postprandial hyperglycemia and frequency of hypoglycemia in IDDM patients on insulin-analog treatment. Multicenter Insulin Lispro Study Group. Diabetes. 1997;46(2):265-270.

3. Bergenstal RM, Tamborlane WV, Ahmann A, et al. Effectiveness of sensor-augmented insulin-pump therapy in type 1 diabetes. $N$ Engl J Med. 2010;363(4):311-320.

4. Gomez AM, Marin Carrillo LF, Munoz Velandia OM, et al. Long-term efficacy and safety of sensor augmented insulin pump therapy with low-glucose suspend feature in patients with type 1 diabetes. Diabetes Technol Ther. 2017;19(2):109-114.

5. Lindholm A, McEwen J, Riis AP. Improved postprandial glycemic control with insulin aspart. A randomized double-blind cross-over trial in type 1 diabetes. Diabetes Care. 1999;22(5):801-805.

6. Eisenbarth GS. Type I diabetes mellitus. A chronic autoimmune disease. N Engl J Med. 1986;314(21):1360-1368.

7. MacCuish AC, Jordan J, Campbell CJ, Duncan LJ, Irvine WJ. Cellmediated immunity in diabetes mellitus; lymphocyte transformation by insulin and insulin fragments in insulin-treated and newly-diagnosed diabetes. Diabetes. 1975;24(1):36-43.

8. Fathman CG, Frelinger JG. T-lymphocyte clones. Annu Rev Immunol. 1983;1:633-655.

9. Hedrick SM, Cohen DI, Nielsen EA, Davis MM. Isolation of cDNA clones encoding T cell-specific membrane-associated proteins. Nature. 1984;308(5955):149-153.

10. Miller GG, Pollack MS, Nell LJ, Thomas JW. Insulin-specific human T cells. Epitope specificity, major histocompatibility complex restriction, and alloreactivity to a diabetes-associated haplotype. J Immunol. 1987;139(11):3622-3629.

11. Naquet P, Ellis J, Tibensky D, et al. T cell autoreactivity to insulin in diabetic and related non-diabetic individuals. J Immunol. 1988;140(8):2569-2578.

12. Aly T, Devendra D, Eisenbarth GS. Immunotherapeutic approaches to prevent, ameliorate, and cure type 1 diabetes. Am J Ther. 2005;12(6):481-490.

13. Culina S, Boitard C, Mallone R. Antigen-based immune therapeutics for type 1 diabetes: magic bullets or ordinary blanks? Clin Dev Immunol. 2011;2011:286248.

14. Vanderlugt CL, Miller SD. Epitope spreading in immune-mediated diseases: implications for immunotherapy. Nat Rev Immunol. 2002;2(2):85-95.

15. Bougneres PF, Landais $\mathrm{P}$, Boisson $\mathrm{C}$, et al. Limited duration of remission of insulin dependency in children with recent overt type I diabetes treated with low-dose cyclosporin. Diabetes. 1990;39(10):1264-1272.

16. Castano L, Boitard C, Bougneres PF. Cyclosporin A suppresses insulin autoantibodies and heterologous insulin antibodies in type I diabetic children. Diabetes. 1988;37(8):1049-1052.

17. Belghith M, Bluestone JA, Barriot S, Megret J, Bach JF, Chatenoud L. TGF-beta-dependent mechanisms mediate restoration of self-tolerance induced by antibodies to CD3 in overt autoimmune diabetes. Nat Med. 2003;9(9):1202-1208.

18. Chatenoud L, Primo J, Bach JF. CD3 antibody-induced dominant self tolerance in overtly diabetic NOD mice. J Immunol. 1997;158(6):2947-2954.

19. Chatenoud L, Thervet E, Primo J, Bach JF. Anti-CD3 antibody induces long-term remission of overt autoimmunity in nonobese diabetic mice. Proc Natl Acad Sci U SA. 1994;91(1):123-127.

20. Penaranda C, Tang Q, Bluestone JA. Anti-CD3 therapy promotes tolerance by selectively depleting pathogenic cells while preserving regulatory T cells. J Immunol. 2011;187(4):2015-2022. 
21. Fife BT, Guleria I, Gubbels Bupp M, et al. Insulin-induced remission in new-onset NOD mice is maintained by the PD-1-PD-L1 pathway. J Exp Med. 2006;203(12):2737-2747.

22. Sherry N, Hagopian W, Ludvigsson J, et al. Teplizumab for treatment of type 1 diabetes (Protege study): 1-year results from a randomised, placebo-controlled trial. Lancet. 2011;378(9790):487-497.

23. Keymeulen B, Walter M, Mathieu C, et al. Four-year metabolic outcome of a randomised controlled CD3-antibody trial in recent-onset type 1 diabetic patients depends on their age and baseline residual beta cell mass. Diabetologia. 2010;53(4):614-623.

24. Kolb H, von Herrath M. Immunotherapy for type 1 diabetes: why do current protocols not halt the underlying disease process? Cell Metab. 2017;25(2):233-241.

25. Pozzilli P, Maddaloni E, Buzzetti R. Combination immunotherapies for type 1 diabetes mellitus. Nat Rev Endocrinol. 2015;11(5):289-297.

26. Long AE, Gillespie KM, Rokni S, Bingley PJ, Williams AJ. Rising incidence of type 1 diabetes is associated with altered immunophenotype at diagnosis. Diabetes. 2012;61(3):683-686.

27. Patterson CC, Dahlquist GG, Gyurus E, Green A, Soltesz G, Group ES. Incidence trends for childhood type 1 diabetes in Europe during 1989-2003 and predicted new cases 2005-20: a multicentre prospective registration study. Lancet. 2009;373(9680):2027-2033.

28. Bach JF, Chatenoud L. The hygiene hypothesis: an explanation for the increased frequency of insulin-dependent diabetes. Cold Spring Harb Perspect Med. 2012;2(2):a007799.

29. Vatanen T, Kostic AD, d'Hennezel E, et al. Variation in microbiome LPS immunogenicity contributes to autoimmunity in humans. Cell. 2016;165(4):842-853.

30. Shoda LK, Young DL, Ramanujan S, et al. A comprehensive review of interventions in the NOD mouse and implications for translation. Immunity. 2005;23(2):115-126.

31. Caramalho I, Rodrigues-Duarte L, Perez A, Zelenay S, Penha-Goncalves $\mathrm{C}$, Demengeot J. Regulatory T cells contribute to diabetes protection in lipopolysaccharide-treated non-obese diabetic mice. Scand J Immunol. 2011;74(6):585-595.

32. Bonifacio E. Predicting type 1 diabetes using biomarkers. Diabetes Care. 2015;38(6):989-996.

33. Insel RA, Dunne JL, Atkinson MA, et al. Staging presymptomatic type 1 diabetes: a scientific statement of JDRF, the Endocrine Society, and the American Diabetes Association. Diabetes Care. 2015;38(10):1964-1974.

34. Noble JA, Erlich HA. Genetics of type 1 diabetes. Cold Spring Harb Perspect Med. 2012;2(1):a007732.

35. Valdes AM, Varney MD, Erlich HA, Noble JA. Receiver operating characteristic analysis of HLA, CTLA4, and insulin genotypes for type 1 diabetes. Diabetes Care. 2013;36(9):2504-2507.

36. Ziegler AG, Bonifacio E, Powers AC, Todd JA, Harrison LC, Atkinson MA. Type 1 diabetes prevention: a goal dependent on accepting a diagnosis of an asymptomatic disease. Diabetes. 2016;65(11):3233-3239

37. Michels A, Zhang L, Khadra A, Kushner JA, Redondo MJ, Pietropaolo M. Prediction and prevention of type 1 diabetes: update on success of prediction and struggles at prevention. Pediatr Diabetes. 2015;16(7):465-484

38. Atkinson MA, von Herrath M, Powers AC, Clare-Salzler M. Current concepts on the pathogenesis of type 1 diabetes - considerations for attempts to prevent and reverse the disease. Diabetes Care. 2015;38(6):979-988.

39. Gale EA, Bingley PJ, Emmett CL, Collier T, European Nicotinamide Diabetes Intervention Trial G. European Nicotinamide Diabetes Intervention Trial (ENDIT): a randomised controlled trial of intervention before the onset of type 1 diabetes. Lancet. 2004;363(9413):925-931.

40. Pearson JA, Wong FS, Wen L. The importance of the Non Obese Diabetic (NOD) mouse model in autoimmune diabetes. J Autoimmun. 2016;66:76-88.

41. Anderson MS, Bluestone JA. The NOD mouse: a model of immune dysregulation. Annu Rev Immunol. 2005;23:447-485.
42. Bluestone JA, Herold K, Eisenbarth G. Genetics, pathogenesis and clinical interventions in type 1 diabetes. Nature. 2010;464(7293):1293-1300.

43. Pozzilli P, Signore A, Williams AJ, Beales PE. NOD mouse colonies around the world--recent facts and figures. Immunol Today. 1993;14(5):193-196.

44. Wen L, Ley RE, Volchkov PY, et al. Innate immunity and intestinal microbiota in the development of Type 1 diabetes. Nature. 2008;455(7216):1109-1113.

45. McLean MH, Dieguez D Jr, Miller LM, Young HA. Does the microbiota play a role in the pathogenesis of autoimmune diseases? Gut. 2015;64(2):332-341.

46. Paun A, Yau C, Danska JS. The influence of the microbiome on type 1 diabetes. J Immunol. 2017;198(2):590-595.

47. $\mathrm{Hu}$ Y, Wong FS, Wen L. Antibiotics, gut microbiota, environment in early life and type 1 diabetes. Pharmacol Res. 2017;119:219-226.

48. Gulden E, Ihira M, Ohashi A, et al. Toll-like receptor 4 deficiency accelerates the development of insulin-deficient diabetes in non-obese diabetic mice. PLoS One. 2013;8(9):e75385.

49. Devaraj S, Tobias P, Jialal I. Knockout of toll-like receptor-4 attenuates the pro-inflammatory state of diabetes. Cytokine. 2011;55(3):441-445

50. Kawai T, Akira S. Toll-like receptors and their crosstalk with other innate receptors in infection and immunity. Immunity. 2011;34(5):637-650.

51. Burrows MP, Volchkov P, Kobayashi KS, Chervonsky AV. Microbiota regulates type 1 diabetes through toll-like receptors. Proc Natl Acad Sci U S A. 2015;112(32):9973-9977.

52. Andre I, Gonzalez A, Wang B, Katz J, Benoist C, Mathis D. Checkpoints in the progression of autoimmune disease: lessons from diabetes models. Proc Natl Acad Sci U S A. 1996;93(6):2260-2263.

53. Bour-Jordan H, Salomon BL, Thompson HL, Szot GL, Bernhard MR, Bluestone JA. Costimulation controls diabetes by altering the balance of pathogenic and regulatory T cells. J Clin Invest. 2004;114(7):979-987.

54. Kriegel MA, Rathinam C, Flavell RA. Pancreatic islet expression of chemokine CCL2 suppresses autoimmune diabetes via tolerogenic CD11c+ CD11b+ dendritic cells. Proc Natl Acad Sci U S A. 2012;109(9):3457-3462.

55. Dahlen E, Dawe K, Ohlsson L, Hedlund G. Dendritic cells and macrophages are the first and major producers of TNF-alpha in pancreatic islets in the nonobese diabetic mouse. J Immunol. 1998;160(7):3585-3593.

56. Serreze DV, Gaedeke JW, Leiter EH. Hematopoietic stem-cell defects underlying abnormal macrophage development and maturation in NOD/ Lt mice: defective regulation of cytokine receptors and protein kinase C. Proc Natl Acad Sci U S A. 1993;90(20):9625-9629.

57. Nikolic T, Geutskens SB, van Rooijen N, Drexhage HA, Leenen PJ. Dendritic cells and macrophages are essential for the retention of lymphocytes in (peri)-insulitis of the nonobese diabetic mouse: a phagocyte depletion study. Lab Invest. 2005;85(4):487-501.

58. Lehuen A, Diana J, Zaccone P, Cooke A. Immune cell crosstalk in type 1 diabetes. Nat Rev Immunol. 2010;10(7):501-513.

59. Tai N, Wong FS, Wen L. The role of the innate immune system in destruction of pancreatic beta cells in NOD mice and humans with type I diabetes. J Autoimmun. 2016;71:26-34.

60. Lee CC, Avalos AM, Ploegh HL. Accessory molecules for toll-like receptors and their function. Nat Rev Immunol. 2012;12(3):168-179.

61. Collins PE, Carmody RJ. The regulation of endotoxin tolerance and its impact on macrophage activation. Crit Rev Immunol. 2015;35(4):293-323.

62. Biswas SK, Lopez-Collazo E. Endotoxin tolerance: new mechanisms, molecules and clinical significance. Trends Immunol. 2009;30(10): 475-487.

63. Piao W, Song C, Chen H, et al. Endotoxin tolerance dysregulates MyD88- and toll/IL-1R domain-containing adapter inducing IFN-betadependent pathways and increases expression of negative regulators of TLR signaling. J Leukoc Biol. 2009;86(4):863-875.

64. Matsushita H, Ohta S, Shiraishi H, et al. Endotoxin tolerance attenuates airway allergic inflammation in model mice by suppression of the T-cell stimulatory effect of dendritic cells. Int Immunol. 2010;22(9):739-747. 
65. Bahrun U, Kimoto M, Tsukamoto H, Tsuneyoshi N, Kohara J, Fukudome K. Preparation and characterization of agonistic monoclonal antibodies against toll-like receptor 4-MD-2 complex. Hybridoma (Larchmt). 2007;26(6):393-399.

66. Bednar KJ, Tsukamoto H, Kachapati K, et al. Reversal of new-onset type 1 diabetes with an agonistic TLR4/MD-2 monoclonal antibody. Diabetes. 2015;64(10):3614-3626.

67. Talmadge JE, Gabrilovich DI. History of myeloid-derived suppressor cells. Nat Rev Cancer. 2013;13(10):739-752.

68. Ramachandran IR, Martner A, Pisklakova A, et al. Myeloid-derived suppressor cells regulate growth of multiple myeloma by inhibiting T cells in bone marrow. J Immunol. 2013;190(7):3815-3823.

69. Chen X, Eksioglu EA, Zhou J, et al. Induction of myelodysplasia by myeloid-derived suppressor cells. J Clin Invest. 2013;123(11):4595-4611.

70. Cheng P, Corzo CA, Luetteke N, et al. Inhibition of dendritic cell differentiation and accumulation of myeloid-derived suppressor cells in cancer is regulated by S100A9 protein. J Exp Med. 2008;205(10):2235-2249.

71. Iwata Y, Furuichi K, Kitagawa K, et al. Involvement of CD11b+ GR-1 low cells in autoimmune disorder in MRL-Fas lpr mouse. Clin Exp Nephrol. 2010;14(5):411-417.

72. Haile LA, von Wasielewski R, Gamrekelashvili J, et al. Myeloid-derived suppressor cells in inflammatory bowel disease: a new immunoregulatory pathway. Gastroenterology. 2008;135(3): 871-881, 881.e1-881.e5.

73. Nagaraj S, Youn JI, Gabrilovich DI. Reciprocal relationship between myeloid-derived suppressor cells and T cells. J Immunol. 2013;191(1): 17-23.

74. Ioannou M, Alissafi T, Boon L, Boumpas D, Verginis P. In vivo ablation of plasmacytoid dendritic cells inhibits autoimmunity through expansion of myeloid-derived suppressor cells. J Immunol. 2013;190(6):2631-2640.

75. Ghazarian L, Diana J, Beaudoin L, et al. Protection against type 1 diabetes upon Coxsackievirus B4 infection and iNKT-cell stimulation: role of suppressive macrophages. Diabetes. 2013;62(11):3785-3796.
76. Xue S, Posgai A, Wasserfall C, et al. Combination therapy reverses hyperglycemia in NOD mice with established type 1 diabetes. Diabetes. 2015;64(11):3873-3884.

77. Ben Nasr M, D’Addio F, Usuelli V, Tezza S, Abdi R, Fiorina P. The rise, fall, and resurgence of immunotherapy in type 1 diabetes. Pharmacol Res. 2015;98:31-38.

78. Louvet C, Szot GL, Lang J, et al. Tyrosine kinase inhibitors reverse type 1 diabetes in nonobese diabetic mice. Proc Natl Acad Sci USA. 2008;105(48):18895-18900.

79. Koulmanda M, Bhasin M, Hoffman L, et al. Curative and beta cell regenerative effects of alpha1-antitrypsin treatment in autoimmune diabetic NOD mice. Proc Natl Acad Sci U S A. 2008;105(42): 16242-16247.

80. Irie J, Wu Y, Kachapati K, Mittler RS, Ridgway WM. Modulating protective and pathogenic CD4+ subsets via CD137 in type 1 diabetes. Diabetes. 2007;56(1):186-196.

81. Kachapati K, Adams D, Bednar K, Ridgway WM. The non-obese diabetic (NOD) mouse as a model of human type 1 diabetes. Methods Mol Biol. 2012;933:3-16.

82. Kachapati K, Bednar KJ, Adams DE, et al. Recombinant soluble CD137 prevents type one diabetes in nonobese diabetic mice. J Autoimmun. 2013;47:94-103.

83. Haller MJ, Gitelman SE, Gottlieb PA, et al. Antithymocyte globulin plus G-CSF combination therapy leads to sustained immunomodulatory and metabolic effects in a subset of responders with established type 1 diabetes. Diabetes. 2016;65(12):3765-3775.

84. von Herrath M, Peakman M, Roep B. Progress in immune-based therapies for type 1 diabetes. Clin Exp Immunol. 2013;172(2):186-202.

85. Michaud JP, Halle M, Lampron A, et al. Toll-like receptor 4 stimulation with the detoxified ligand monophosphoryl lipid A improves Alzheimer's disease-related pathology. Proc Natl Acad Sci U S A. 2013;110(5):1941-1946.
ImmunoTargets and Therapy

\section{Publish your work in this journal}

ImmunoTargets and Therapy is an international, peer-reviewed open access journal focusing on the immunological basis of diseases, potential targets for immune based therapy and treatment protocols employed to improve patient management. Basic immunology and physiology of the immune system in health, and disease will be also covered. In addition, the journal will focus on the impact

\section{Dovepress}

of management programs and new therapeutic agents and protocols on patien perspectives such as quality of life, adherence and satisfaction. The manuscript management system is completely online and includes a very quick and fair peer-review system, which is all easy to use. Visit http://www.dovepress.com/ testimonials.php to read real quotes from published authors. 